\title{
Conditions of Global Health Crisis Decision-Making-An Ethical Analysis
}

\author{
Elizabeth Fenton • Kata Chillag
}

Received: 27 March 2020 / Accepted: 10 March 2021 / Published online: 16 April 2021

(C) Journal of Bioethical Inquiry Pty Ltd. 2021

\begin{abstract}
The circumstances of a public health emergency (PHE) shape reasoning and decision-making in ways that deviate from routine circumstances, where adherence to established values, principles, and methodologies is expected. Understanding what drives these deviations is critical to assessing their ethical consequences. In this paper we describe four conditions that influence decision-making during PHEs, in particular regarding the deployment and conduct of research on experimental or novel biomedical interventions. These four conditions are politicization, urgency, uncertainty, and fear. We argue that taken together these four conditions create pressure to address the most visible targets of immediate crisis events, driving emphasis on research and development of biomedical interventions. However, this emphasis raises ethical concerns regarding the extent to which attention to and investment in the underlying causes of PHEs, particularly impoverished global public health infrastructure, is diminished as a result.
\end{abstract}

Keywords Public health emergencies $\cdot$ Ethics .

Research · Justice $\cdot$ Ebola

E. Fenton $(\bowtie)$

Bioethics Centre, University of Otago, 71 Frederick Street,

Dunedin, New Zealand

e-mail: Elizabeth.fenton@otago.ac.nz

K. Chillag

Department of Public Health, Davidson College, Davidson, NC, USA

\section{Introduction}

The circumstances of a public health emergency (PHE) shape reasoning and decision-making in ways that deviate from routine circumstances, where adherence to established values, principles, and methodologies is expected. Understanding what drives these deviations is critical to assessing their ethical consequences. In this paper we describe four conditions that influence decision-making during PHEs, in particular regarding the deployment of and conduct of research on experimental or novel biomedical interventions.

Research during PHEs has been the subject of considerable ethical scrutiny and analysis, especially in the wake of the 2014-2016 Ebola epidemic in west Africa. In a 2020 report the Nuffield Council on Bioethics evaluates the ethical pressures on the research context and process during PHEs and shows that research can be conducted ethically in global health crises given the appropriate preparation and ethical orientation (Nuffield Council 2020). However, this and other similar documents that have emerged in the period after the 2014-2016 west African epidemic neglect two issues that fall outside the scope of ethical conduct of research. The first is the important prior question of what pressures exist to initiate and conduct research during PHEs, and where they originate. The Nuffield report notes that conditions including urgency, uncertainty, and fear make the conduct of research in PHEs difficult. We suggest that together with a critical fourth condition, politicization, these conditions not only influence the conduct of research during an emergency but also create 
pressure to initiate research as part of PHE response. In Part I of this paper we examine these four conditions in more detail.

The second issue, addressed in Part II, is whether research and development of biomedical interventions during PHEs is ethically permissible or ethically required. It might be considered ethically required to the extent that it acts as a corrective to funding priorities that have long neglected research on diseases that affect the poorest regions and populations, those most likely to experience a public health crisis (Olliaro, Horby, and Torreele 2015). Biomedical research could be considered ethically permissible to the extent that it strengthens our capacity to respond effectively to disease outbreaks in the future or offers at least a potential benefit, and little risk, to those immediately affected. However, other potential consequences raise concerns about whether research and development of biomedical interventions during PHEs is either ethically permissible or required. The first concern is that research on experimental or novel interventions acts as a diversion of investment from other important public health goals, in particular from investment in the more demanding and longerterm measures needed to improve the conditions under which PHEs emerge and spread. Second is the related concern that as the power and promise of biomedical interventions begins to dominate the discourse over PHE response, moral imperatives to address the complex causal contributors to global PHEs weaken. The force of those moral imperatives is at risk of being eclipsed by the potential "magic bullet" solutions offered by biomedical research.

\section{Part I: Four Conditions of Global Health Crisis Decision-Making}

\section{Politicization}

Public health is a political discipline and operates in a political context. It requires government and collective action, focuses on health problems with social, economic, and political determinants, and is grounded in social justice (Powers and Faden 2006). Yet public health is also liable to be politicized in the sense of being manipulated to serve a political agenda that may stand in contrast to the goals of public health itself. The politicization of public health occurs in at least three ways. First, public health, and public health emergencies in particular, can be used as a justification for pursuing political goals that are not necessarily connected to public health. For example, history is replete with instances of public health fears being used to stoke anti-immigrant sentiment (Markel 2004). Fears over the spread of COVID-19 in the United States were used by the Trump administration to justify even tighter restrictions on claims to asylum at the US-Mexico border, a move criticized by immigration advocates as "the culmination of a three-year push to end asylum protections" for Central American migrants (Rose and Falk 2020; Lind 2020).

Second, public health is politicized when political considerations influence the imposition and uptake of measures designed to protect the public. This can occur even at the highest levels of global health governance. The World Health Organization (WHO), for example, must weigh the need to enforce the International Health Regulations (IHR) against the need for the cooperation (and funding) of member states (Gostin and Wetter 2020). When the WHO delayed declaring the 2014-2016 west African Ebola epidemic as a Public Health Emergency of International Concern (PHEIC), out of concern to avoid further damage to already fragile economies, its decision was widely criticized on the grounds that it allowed the epidemic to accelerate and endangered public health (Kamradt-Scott 2016). Support for public health measures during the COVID-19 pandemic, such as lockdowns and face masks, has been subject to domestic politics in a range of contexts (Woolhandler et al. 2021).

Third, public health is politicized when it is conceived of as an issue of national security. Public health, like all issues not directly related to a state's ability to defend itself against external threats, has traditionally fallen outside the realm of "high politics" or political issues given the highest priority because of their relevance to state security. However, as states came to understand the potential for infectious diseases to undermine economies and political and social stability, particularly with the growth of the HIV/AIDS pandemic through the 1980s and 1990 s, public health was increasingly "securitized" and ascended the political agendas of affluent developed countries (Youde 2016; McInnes, Kelley and Youde 2019). Global public health emergencies are now liable to be described as much in terms of security as in terms of health, as, for example, when the 2014-2016 Ebola epidemic was described by then U.S. President Barack Obama as "a national security priority" and by the United Nations Security 
Council as "a threat to international peace and security" (White House 2014; United Nations Security Council 2014).

One advantage of couching threats to public health in terms of national security is that it directs more political, and potentially public, attention to public health and requires that it be taken seriously. On the other hand, critics of securitization argue that it focuses too narrowly on infectious diseases that inspire fear among Western policymakers, neglecting health issues that cause higher levels of morbidity and mortality. Securitization imposes a "crisis mindset" concerned primarily with stopping the spread of disease, rather than focusing on long-term approaches to reducing the likelihood of future outbreaks. It also sidelines other important moral reasons to be concerned about global health, such as a humanitarian imperative and human rights (Youde 2016; Davies 2009). During a public health crisis a political concern with security might also be invoked as a justification for measures, such as border controls, travel restrictions, and quarantine, that can carry negative social consequences. When targeted at specific groups or populations these measures can be stigmatizing, can diminish support for contributing to response efforts in the worst affected areas, and are not always proportional or supported by scientific evidence (Presidential Commission for the Study of Bioethical Issues 2015; Miles 2015).

Political concern with health security often also goes hand in hand with the pharmaceuticalization of public health threats, where pursuit of "magic bullet" interventions can eclipse political engagement with the underlying socioeconomic issues that contribute to the causes of the crisis (Davies 2008). A pharmaceutical intervention focusing on "a precise target in a circumscribed event with direct security relevance for domestic populations" will be an easier sell politically than a long-term commitment to addressing "complex socioeconomic problems whose domestic relevance is uncertain" (RoemerMahler and Elbe 2016, 493). Moreover, where a health security threat has been identified, an "exceptional policy space" opens up in which key norms and rules governing the development and approval of pharmaceutical interventions can be modified to expedite an effective and politically acceptable response to the threat (Roemer-Mahler and Elbe 2016, 495; Edwards 2013).

Ironically the politicization of public health emergencies in each of these three ways obscures the fact that the true causes of these events are themselves political. The factors that contributed to the scale and spread of the 2014-2016 Ebola epidemic in west Africa, for example, must be understood as deeply rooted in a historical and political context that includes civil war, political instability, decades of underfunding of public services following structural adjustment programmes imposed by global institutions like the International Monetary Fund and World Bank, corruption, extreme economic inequality, increased urban population density and slums, and exclusion of large parts of the population from institutions of governance and formal healthcare (Alexander, Sanderson, and Marathe 2015; McPake et al. 2015; Wilkinson and Leach 2015).

\section{Urgency}

Urgency is a sense of imminent danger or accelerating threat that manifests in public health emergencies as both temporal urgency and moral urgency. Temporal urgency, generated by the speed and spread of an epidemic or crisis event, and the threat it poses to other communities or countries, encompasses the need to control an epidemic. A focus on health security fuels temporal urgency by promoting "the perception of an immediate, potentially irreversible danger that creates a perceived need for rapid response" (Roemer-Mahler and Elbe 2016, 492). The combined force of an urgent security threat again drives a focus on biomedical solutions to a crisis, rather than on longer-term policy options that engage with the socioeconomic and political factors that contribute to global public health emergencies (Roemer-Mahler and Elbe 2016). Temporal urgency can mobilize resources for research during an emergency, facilitate its rapid implementation in the face of bureaucratic and other logistical obstacles, and foster innovation and multidisciplinary collaboration. However, it can also lead to a focus on a narrow set of outcomes and oversimplification of what is required to achieve those outcomes, privileging short-term solutions to the most visible or acute manifestations of crisis over those that address its fundamental causes.

Moral urgency is driven by humanitarian concerns and has ethical implications for decisions about how and where resources should be used. For example, the ethics advisory panel to WHO during the 2014-2016 Ebola epidemic argued that the high case-fatality rate of the disease, and lack of any existing treatments, ethically justified use of experimental pharmaceutical 
interventions that had not previously been tested in humans (World Health Organiztion (WHO) 2014). Moral urgency makes ethically palatable a treatment and research pathway that might otherwise be questionable by established medical and research ethics standards. Similarly, when researchers debated the use of orthodox clinical trial design for experimental treatments for Ebola, notably randomization to placebo, they prioritized the moral urgency of providing the treatments to as many patients as possible over competing ethical considerations (Adebamowo et al. 2014; Sissoko et al. 2016).

\section{Uncertainty}

Uncertainty reflects either a lack of relevant information (epistemic uncertainty) or a lack of clarity about the best or most appropriate course of action (moral uncertainty). Both are paradigmatic of public health emergencies. Scientific uncertainty, a form of epistemic uncertainty present in all public health practice and research, may be amplified or managed differently in emergencies where (it is perceived that) there is little time to adjudicate it through standard processes. The drive to resolve epistemic uncertainty through clinical research can in turn create moral uncertainties, particularly about what types of research are needed, feasible, and ethical under the circumstances. In some public health emergencies the epistemic uncertainty perceived to be most pressing surrounds the safety and effectiveness of novel or experimental interventions. During the 2014-2016 Ebola epidemic epistemic uncertainty gave rise to moral uncertainty about the appropriate design of clinical trials (Calain 2018; Caplan, Plunkett, and Levin 2015). Some argued that although effectiveness was uncertain, the comparative certainty of death for those infected with Ebola justified giving experimental interventions to as many patient participants as possible, rather than randomizing some to a control arm (Adebamowo et al. 2014). Others argued that existing uncertainty about potential benefits or harms provided the ethical justification for randomization (Cox, Borio, and Temple 2014; Dawson 2015). The debate over trial design also obscured other moral uncertainties raised by the proposed trials, such as whether patients and communities in extremis could understand that the research would be unlikely to benefit them, could evaluate the value of this research, or could meaningfully consent to participate.
Fear

Public and political support for public health is connected to fear, particularly fear of disease agents that originate elsewhere and pose an existential threat to a particular way of life, the fear "that what is 'over there' could come 'here"' (Garrett 2000,13). Dramatic events, such as a disease outbreak or bioterrorist attack, create a "policy window" for public health, in which fear surrounding the event focuses public and legislative attention on public health activities (Avery 2014).

Yet fear can also be manipulated. Some have argued that during the 2014-2016 Ebola west Africa epidemic a politics of fear was used to justify short-term response efforts designed more to quell domestic fears of infection in countries outside the affected area than to address the deeper causes of the epidemic at its source. Global fears about state failure, risks to regional and global security, and the spread of infection beyond west Africa drove global response efforts with largely self-serving goals - i.e., to stop what is 'over there' from coming 'here.' (McInnes 2016). The pursuit of self-interested protection by states is evident time and again as global health crises emerge (Davies 2009). Moreover, response efforts driven by fear and immediate self-preservation lack the sustained levels of political commitment needed to extend into the more complex territory of addressing the background conditions that give rise to infectious diseases (Nunes 2017; Davies 2009; Youde 2016). It was noted that during the 2018-2020 Ebola outbreak in eastern Democratic Republic of the Congo Western media attention on the region was largely driven by fear of the spread of Ebola beyond Africa, rather than concern for the Congolese people. Any such concern would have motivated attention and intervention on the conditions in the region long before that outbreak (Karan 2018).

Fear and desperation in the face of a public health emergency can heighten political and other societal and institutional pressures to take rapid action. While rapid action might be appropriate, the hopelessness and despair that characterize a state of desperation can create pressure to act without sufficient consideration of feasibility or available information or even to pursue action that is not supported by available scientific evidence. Desperation can distort the force of compassion and give any possibility of rescue the weight of a moral demand (Caplan 2015). This weight was reflected in the WHO ethics advisory panel's conclusion that 
deploying experimental interventions in the context of the Ebola epidemic in west Africa was not simply ethically permissible but "an ethical imperative" (World Health Organization (WHO) 2014, 5).

Fear and desperation can also distort both patients' and health workers' motivations for participating in clinical research during a public health emergency. Potential participants are more vulnerable in this context to the therapeutic misconception or the mistaken belief that participating in research will, or is intended to, benefit them individually, that its purpose is therapeutic rather than scientific (World Health Organization (WHO) 2016a; Henderson et al. 2007). This may be compounded or expressed differently in settings in which research is uncommon, access to education is limited or in relation to other contextual factors (Bhutta 2004). This misconception is not limited to participants but can be mutually reinforced among communities, policymakers, and researchers, reflecting the understandable desire to find solutions to urgent public health problems and alleviate suffering. In an emergency context, research participants are also vulnerable to a "humanitarian misconception," in which research is conflated with aid, leading individuals to believe that they must participate in research in order to receive aid (O'Mathuna 2015). In the chaotic and terrifying environment of a major public health emergency, humanitarian and therapeutic misconceptions are exacerbated, as multiple organizations become involved in providing aid, conducting research, or both, and humanitarian and scientific goals are conflated.

\section{Part II: Ethical Concerns}

Taken together, politicization, urgency, uncertainty, and fear create pressure to address the most visible targets of immediate crisis events. As was evident during the 2014-2016 Ebola epidemic this pressure can significantly contribute to a surge in research endeavours trying to take advantage of particular, sometimes unique, circumstances. Some of these endeavours bear fruit, others do not.

These four conditions create pressure to focus on research and development of biomedical interventions and so drive what might be called an "R\&D turn" in global PHE response. The R\&D turn raises two ethical concerns. First, it risks diverting attention from other important public health goals, absorbing both the financial resources and the political will of wealthy nations that could otherwise be invested in improving the health conditions of the world's poor. Historians note that time and again public health crises fade from public consciousness once the immediate crisis is over, and the social and public health conditions that gave rise to them remain unchanged (Markel 2004; Youde 2016). Whereas research and development of biomedical interventions provides a concrete target at which wealthy nations can direct their global health resources, efforts to improve health infrastructure and build universal basic healthcare are complex, amorphous, and possibly limitless by comparison and therefore a harder sell politically. Yet these are precisely the investments that are needed to prevent public health crises and, importantly, to ensure that any new intervention can be effective. New interventions are an important public health tool, but their practical success stands or falls on the existence of a health system that can deliver them safely. Functioning and robust health systems, even if limited, are essential to preventing epidemics (McDermott 2018).

Second, as a response to the demands of global health justice the $\mathrm{R} \& \mathrm{D}$ turn is inadequate. In its $R \& D$ Blueprint for Action to Prevent Epidemics the WHO states that factors such as more frequent travel, globalized trade, and greater interconnectedness between countries make infectious disease outbreaks "as inevitable as they remain unpredictable" (World Health Organization (WHO) 2016b). Yet these factors are at best secondary to the structural and systemic vulnerabilities within populations that are the real drivers of infectious disease outbreaks. Poverty, lack of access to healthcare, impoverished health infrastructure, and political instability are just some of the significant causal factors for which the R\&D blueprint offers no solutions. The securitization of global public health that helps drive "pharmaceuticalization" and the magic bullet narrative obscures other important reasons why people care about and work to improve it, such as a humanitarian imperative, and a desire to tackle root causes and improve living conditions more broadly (Davies 2009; Youde 2016). Global public health is underpinned by a fundamental commitment to health equity, which in turn reflects a commitment to justice in the social and economic systems in which people live. While the lack of safe, effective interventions for diseases like Ebola is unjust, reflecting a gross inequity between what is available to meet the health needs of the global rich versus the global poor, the R\&D turn risks neglecting the 
arguably prior issues of justice that are critical to the prevention of public health crises. It also risks obviating the collective social responsibility of wealthy nations and global health funders to commit to a public health approach that will improve the health conditions of the world's poor, and, in turn, global health, "which is good for everyone, no matter where they live" (Markel 2014, 636).

The WHO's ethical green light for making experimental interventions available to patients was the impetus for much of the clinical research that was conducted during the 2014-2016 Ebola epidemic in west Africa. While some bioethicists criticized the WHO for "pointless grandstanding in the face of a pandemic that requires a public health response" (Schuklenk 2014), the emerging debate was not whether to conduct clinical trials of experimental Ebola interventions but how to conduct them (Caplan, Plunkett, and Levin 2015; Schopper et al. 2017). While trial design, fair access, regulatory issues, and protocol approval processes are important ethical issues to consider in any clinical research, these debates obscured the fact that the trials would almost certainly yield few benefits during the 2014-2016 epidemic and that the epidemic would likely wane before there were sufficient data to evaluate the efficacy or effectiveness of the interventions. This discourse also obscured the fact that even if such interventions proved efficacious, their public health success would directly or indirectly rely on fundamental public health measures such as case finding, contact tracing, and more generally, in building public trust. Without extensive work in affected communities to build both public health infrastructure and trust, no single intervention can end an epidemic or prevent another one, a lesson that has been learned and relearned in numerous contexts.

The power of the magic bullet narrative is such that these concerns and logistical issues are often marginalized, obscured by the political appeal of a "win" or a "solution." Also marginalized is the recognition that the primary causes of global health crises are typically not amenable to narrowly-focused scientific or technological solutions (Degeling, Johnson, and Mayes 2015). Deeply entrenched poverty, created by decades - lifetimes - of social injustice at an individual, national, and international level, will continue to create the circumstances for further disease epidemics. Certainly, effective vaccines and biomedical therapies for infectious diseases are an invaluable contribution to global public health, but their effectiveness depends on a comprehensive public health strategy that includes building infrastructure and trust related to their implementation. In the absence of a long term, global effort to address the underlying conditions that create public health crises in impoverished regions, infectious diseases will continue to outstrip our capacity to deal with them using biomedical interventions alone (Patel and Phillips 2015). Nor are these concerns limited to lowresource contexts. The devastating and disproportionate impact of the COVID-19 pandemic on persons of colour in the United States has been blamed, at least in part, on long-standing social, economic, and health inequities, and a healthcare system inaccessible to many (Gostin 2020; Centers for Disease Control and Prevention 2020).

It might be argued that since the underlying political and economic conditions and deeper structural causes of public health emergencies cannot be solved rapidly, a push for greater efforts towards R\&D is both expedient and ethically required to relieve as much immediate suffering as possible. While this argument makes some sense from within the "crisis mentality" of a public health emergency, characterized, as described above, by politicization, urgency, uncertainty, and fear, it does not obviate the need, even the obligation, to engage with these structural causes. The danger of the argument from expediency is that the underlying conditions and structural causes of PHEs are left to founder in the "too hard" basket, or repeatedly relegated to a future nonemergency time period that will never arrive, given that urgent public health crises fuelled by unjust social and economic arrangements occur continuously. Global PHE response should be construed broadly, to include not only the reactive response to an immediate (and visible) crisis event but also the long-term response to the ongoing, underlying crisis of which the immediate event is just the latest instantiation.

Reflecting back on the immense pressure emerging and re-emerging infectious diseases placed on global public health infrastructure at the end of the twentieth century, Laurie Garrett notes that the goal of shoring up that infrastructure to deal with future crises "could not be a technological quick fix. Rather, society needed to take aim at a far more complex — and elusive - target, comprised not just of the fruits of scientific labor but also of politics, sociology, economics, and even elements of religion, philosophy, and psychology" (Garrett 2000, 3). Public health and humanitarian crises 
highlight our ongoing failure to hit this target in the twenty years since Garrett described it.

\section{References}

Adebamowo, C., O. Bah-Sow, F. Binka, et al. 2014. Randomised controlled trials for Ebola: Practical and ethical issues. Lancet 384(9952): 1423-1424.

Alexander, K.A., C.E. Sanderson, M. Marathe, et al. 2015. What factors might have led to the emergence of Ebola in West Africa? PLoS Neglected Tropical Diseases 9(6): e0003652.

Avery, G. 2014. Bioterrorism, fear, and public health reform: Matching a policy solution to the wrong window. Public Administration Review 64(3): 275-288.

Bhutta, Z.A. 2004. Beyond informed consent. Bulletin of the World Health Organization 82: 771-777.

Calain, P. 2018. The Ebola clinical trials: A precedent for research ethics in disasters. Journal of Medical Ethics 44(1): 3-8.

Caplan, A.L. 2015. Morality in a time of Ebola. Lancet 385(9971): e16-e17.

Caplan, A.L., C. Plunkett, and B. Levin. 2015. Selecting the right tool for the job. American Journal of Bioethics 15(4): 4-10.

Centers for Disease Control and Prevention (CDC). 2020. Health equity considerations and racial and ethnic minority groups. www.cdc.gov/coronavirus/2019-ncov/community/healthequity/race-ethnicity.html. Accessed September 1, 2020.

Cox, E., L. Borio, and R. Temple. 2014. Evaluating Ebola therapies - the case for RCTs. New England Journal of Medicine 371(25): 2350-2351.

Davies, S.E. 2008. Securitizing infectious disease. International Affairs 84(2): 295-313.

- 2009. Global Politics of Health. Malden, MA: Polity Press.

Dawson, L. 2015. Not All RCTs are created equal: Lessons from early AIDS trials. American Journal of Bioethics 15(4): 4547.

Degeling, C., J. Johnson, and C. Mayes. 2015. Impure politics and pure science: Efficacious Ebola medications are only a palliation and not a cure for structural disadvantage. American Journal of Bioethics 15(4): 43-45.

Edwards, S.J. 2013. Ethics of clinical science in a public health emergency: Drug discovery at the bedside. American Journal of Bioethics 13(9): 3-14.

Garrett, L. 2000. Betrayal of trust: The collapse of global public health. New York: Hyperion.

Gostin, L.O. 2020. The great coronavirus pandemic of 2020: 7 critical lessons. JAMA Forum, August 13. jamanetwork. com/channels/health-forum/fullarticle/2769600. Accessed September 1, 2020.

Gostin, L.O., and S. Wetter. 2020. Using Covid-19 to strengthen the WHO: Promoting health and science above politics. Milbank Quarterly Opinion, May 6. doi.https://doi. org/10.1599/mqop.2020.0506.

Henderson, G.E., L.R. Churchill, A.M. Davis, et al. 2007. Clinical trials and medical care: Defining the therapeutic misconception. PLoS Med 4(11): e324.
Kamradt-Scott, A. 2016. WHO's to blame? The World Health Organization and the 2014 Ebola epidemic in West Africa. Third World Quarterly 37(3): 401-418

Karan, A. 2018. Caring about the Congo shouldn't require an Ebola epidemic. The Boston Globe, December 5. www. bostonglobe.com/ideas/2018/12/05/caring-about-congos houldn-require-ebola-epidemic/n GrAwt 0 CVJNUkAPAXzr85L/story.html. Accessed March 18, 2020.

Lind, D. 2020. Leaked Border Patrol memo tells agents to send migrants back immediately-ignoring asylum law. ProPublica, April 2. www.propublica.org/article/leakedborder-patrol-memo-tells-agents-to-send-migrants-backimmediately-ignoring-asylum-law. Accessed September 1, 2020.

Markel, H. 2004. When germs travel. New York: Vintage Books. - 2014. Ebola fever and global health responsibilities. The Milbank Quarterly 92(4): 633-639.

McDermott J. (2018) Both in rich and poor countries, universal health care brings huge benefits. The Economist 414(9086). https://www.economist.com/special-report/2018/04/28/bothin-rich-and-poor-countries-universal-health-care-bringshuge-benefits. Accessed 24 March 2021.

McInnes, C. 2016. Crisis! What crisis? Global health and the 2014-15 West African Ebola outbreak. Third World Quarterly 37(3): 380-400.

McInnes, C., K. Lee, and J. Youde. 2019. Global health politics: An introduction. In Oxford Handbook of Global Health Politics, edited by C. McInnes, K. Lee, and J. Youde. Oxford: Oxford University Press.

McPake, B., S. Witter, S. Ssali, H. Wurie, J. Namakula, and F. Ssengooba. 2015. Ebola in the context of conflict affected states and health systems: Case studies of Northern Uganda and Sierra Leone. Conflict and Health 9: 23.

Miles, S.H. 2015. Kaci Hickox: Public health and the politics of fear. American Journal of Bioethics 15(4): 17-19.

Nuffield Council on Bioethics. 2020. Research in global health emergencies: Ethical issues. www.nuffieldbioethics. org/publications/research-in-global-health-emergencies. Accessed March 18, 2020.

Nunes, J. 2017. Doctors against Borders: Médicins Sans Frontières and global health security. In The politics of fear: Médecins sans Frontières and the West African Ebola Epidemic, edited by M. Hofman, and S. Au, 3-24. New York: Oxford University Press.

Olliaro, P., P. Horby, and E. Torreele. 2015. Health security and rights in times of emerging health threats: Towards a new way of doing essential health research and development. Lancet 385 (9980):1892-1893.

O'Mathuna, D. 2015. Research ethics in the context of humanitarian emergencies. Journal of Evidence Based Medicine 8(1): 31-35.

Patel, M.S., and C.B. Phillips. 2015. Health security and political and economic determinants of Ebola. Lancet 386(9995): 737-738.

Powers, M., and R. Faden. 2006. Social justice: The moral foundations of public health and health policy. New York: Oxford University Press.

Presidential Commission for the Study of Bioethical Issues. 2015. Ethics and Ebola: Public health planning and response. ht t p s : / / bi o ethicsarchive.georgetown. 
edu/pcsbi/sites/default/files/Ethics-and-Ebola_PCSBI_508. pdf. Accessed March 18, 2020

Roemer-Mahler, A., and S. Elbe. 2016. The race for Ebola drugs: Pharmaceuticals, security and global health governance. Third World Quarterly 37(3): 487-506.

Rose, J., and M. Falk. 2020. Ending "Asylum as we know it": Using pandemic to expel migrants, children at border. National Public Radio News, August 6. www.npr.org/2020 /08/06/898937378/end-of-asylum-using-the-pandemic-toturn-away-migrants-children-seeking-refuge. Accessed September 1, 2020.

Schopper, D., R. Ravinetto, L. Schwartz, et al. 2017. Research ethics governance in times of Ebola. Public Health Ethics 10(1): 49-61.

Schuklenk, U. 2014. Bioethics and the Ebola outbreak in West Africa. Developing World Bioethics 14(3): ii-iii.

Sissoko, D., C. Laouenan, E. Folkesson, et al. 2016. Experimental treatment with favipiravir for Ebola virus disease (the JIKI Trial): A historically controlled, single-arm proof-of-concept trial in Guinea. PLoS Medicine 13(3): e1001967

United Nations Security Council. 2014. Resolution 2177. www. securitycouncilreport.org/atf/cf/\%7B65BFCF9B-6D27-4E9 C-8CD3-CF6E4FF96FF9\%7D/S_RES_2177.pdf. Accessed March 18, 2020.

White House. 2014. President Obama provides an update on the U.S.-led response to Ebola. https://obamawhitehouse. archives.gov/ebola-response. Accessed March 18, 2020
Wilkinson, A., and M. Leach. 2015. Briefing: Ebola-myths, realities, and structural violence. African Affairs 114(454): 136 148.

Woolhandler, S., D.U. Himmelstein, S. Ahmed, et al. 2021. Public policy and health in the Trump era. Lancet 397: 705-753.

World Health Organization (WHO). 2014. Ethical considerations for the use of unregistered interventions for Ebola virus disease. http://apps.who.int/iris/bitstream/handle/10665 / $130997 / \mathrm{WHO}_{-} \mathrm{HIS}_{-}$KER_GHE_14.1_eng. pdf;jsessionid=549DA5A068BB52940EA6ED907BAC6 A34? sequence=1. Accessed March 18, 2020.

. 2016a. Guidance for managing ethics issues in infectious disease outbreaks. https://apps.who. int/iris/bitstream/handle/10665/250580/9789241549837eng.pdf?sequence=1. Accessed March 18, 2020.

- 2016b. An R\&D blueprint for action to prevent epidemics: Plan of action. https://www.who. int/blueprint/about/r_d_blueprint_plan_of_action. $p d f ? u a=1$. Accessed March 18, 2020.

Youde, J. 2016. High politics, low politics, and global health. Journal of Global Security Studies 1(2): 157-170.

Publisher's note Springer Nature remains neutral with regard to jurisdictional claims in published maps and institutional affiliations. 